\title{
Epigenetic switch involved in activation of pioneer factor FOXA1-dependent enhancers
}

\author{
Aurélien A. Sérandour, ${ }^{1,2,3}$ Stéphane Avner, ${ }^{1,2,3,7}$ Frédéric Percevault, ${ }^{1,2,3,7}$ \\ Florence Demay, ${ }^{1,3,4}$ Maud Bizot, ${ }^{1,2,3}$ Céline Lucchetti-Miganeh, ${ }^{1,2,3}$ \\ Frédérique Barloy-Hubler, ${ }^{1,2,3}$ Myles Brown, ${ }^{5}$ Mathieu Lupien, ${ }^{6}$ \\ Raphaël Métivier, ${ }^{1,2,3}$ Gilles Salbert, ${ }^{1,2,3,9}$ and Jérôme Eeckhoute ${ }^{1,2,3,8,9}$
}

${ }^{1}$ Université de Rennes 1, 35065 Rennes, France; ${ }^{2}$ CNRS, UMR 6026, équipe SPARTE, labellisée "Ligue nationale contre le cancer," Campus de Beaulieu, 35042 Rennes, France; ${ }^{3}$ Université européenne de Bretagne, 35000 Rennes, France; ${ }^{4}$ CNRS, UMR 6026, équipe RED, Campus de Beaulieu, 35042 Rennes, France; ${ }^{5}$ Division of Molecular and Cellular Oncology, Department of Medical Oncology, Dana-Farber Cancer Institute, Boston, Massachusetts 02115, USA; ${ }^{6}$ Department of Genetics, Norris Cotton Cancer Center, Dartmouth Medical School, Lebanon, New Hampshire 03756, USA

\begin{abstract}
Transcription factors (TFs) bind specifically to discrete regions of mammalian genomes called cis-regulatory elements. Among those are enhancers, which play key roles in regulation of gene expression during development and differentiation. Despite the recognized central regulatory role exerted by chromatin in control of TF functions, much remains to be learned regarding the chromatin structure of enhancers and how it is established. Here, we have analyzed on a genomicscale enhancers that recruit FOXAl, a pioneer transcription factor that triggers transcriptional competency of these cisregulatory sites. Importantly, we found that FOXA1 binds to genomic regions showing local DNA hypomethylation and that its cell-type-specific recruitment to chromatin is linked to differential DNA methylation levels of its binding sites. Using neural differentiation as a model, we showed that induction of FOXAl expression and its subsequent recruitment to enhancers is associated with DNA demethylation. Concomitantly, histone H3 lysine 4 methylation is induced at these enhancers. These epigenetic changes may both stabilize FOXA1 binding and allow for subsequent recruitment of transcriptional regulatory effectors. Interestingly, when cloned into reporter constructs, FOXAl-dependent enhancers were able to recapitulate their cell type specificity. However, their activities were inhibited by DNA methylation. Hence, these enhancers are intrinsic cell-type-specific regulatory regions of which activities have to be potentiated by FOXAl through induction of an epigenetic switch that includes notably DNA demethylation.
\end{abstract}

[Supplemental material is available for this article. The microarray data from this study have been submitted to the NCBI Gene Expression Omnibus (http:// www.ncbi.nlm.nih.gov/geo/) under accession no. GSE21513.]

Mammalian transcription factors (TFs) regulate gene expression via different classes of cis-regulatory elements including promoters, enhancers, silencers, and insulators (ENCODE Project Consortium et al. 2007). These DNA regulatory elements control gene expression in a coordinated fashion (Cecchini et al. 2009; Farnham 2009; Phillips and Corces 2009; Visel et al. 2009b) and allow for tissue-specific gene regulation (Eeckhoute et al. 2009b; Heintzman et al. 2009; Visel et al. 2009a; Lefterova et al. 2010).

Different classes of TFs act primarily through binding to distinct types of cis-regulatory elements (Eeckhoute et al. 2009b; Farnham 2009; Cheung and Kraus 2010). For instance, the Forkhead family member FOXA1 is a prototypic TF that mainly operates through binding to enhancers (Zaret 1999; Lupien et al. 2008). FOXA1 plays an important role in development and differentiation of multiple organs and has also been involved in cancer including breast and prostate cancer (Zaret 1999; Friedman and

\footnotetext{
${ }^{7}$ These authors contributed equally to this work.

${ }^{8}$ Present address: INSERM UMR1011-Bâtiment J\&K, Univ. Lille-Nord de France, Faculté de Médecine de Lille-Pôle Recherche, Boulevard du Professeur Leclerc, 59045 Lille cedex, France.

${ }^{9}$ Corresponding authors.

E-mail gilles.salbert@univ-rennes1.fr.

E-mail jerome.eeckhoute@inserm.fr.

Article published online before print. Article, supplemental material, and publication date are at http://www.genome.org/cgi/doi/10.1101/gr.111534.110.
}

Kaestner 2006; Mirosevich et al. 2006; Nakshatri and Badve 2009; Nucera et al. 2009). The FOXA1 functional role at enhancers is particular because this factor has the noticeable intrinsic ability to open condensed chromatin structures (Crowe et al. 1999; Cirillo et al. 2002; Belikov et al. 2009). Hence, FOXA1 is believed to scan chromatin for enhancers with forkhead motifs and to trigger their transcriptional competency through initial chromatin decompaction (Zaret 1999; Carroll et al. 2005; Eeckhoute et al. 2006; Sekiya et al. 2009). According to this specific role, FOXA1 has been designated a "pioneer" transcription factor. In line with this concept, FOXA1 binding allows subsequent recruitment of collaborating transcription factors to the $A l b$ gene enhancer during liver differentiation (Zaret 1999). Recently, a role for FOXA1 in allowing the engagement of several nuclear receptors onto chromatin has also been identified (Carroll et al. 2005; Laganiere et al. 2005; Belikov et al. 2009; Wang et al. 2009). These studies have revealed that cell-type-specific regulation of gene expression by FOXA1 involves differential FOXA1 recruitment to enhancers in order to cooperate with distinct nuclear receptors (i.e., the estrogen receptor [ESR1] in breast cells and the androgen receptor [AR] in prostate cells) (Gao et al. 2003; Lupien et al. 2008; Eeckhoute et al. 2009a; Wang et al. 2009).

Chromatin structure remodeling is functionally linked to epigenetic changes that include modulation of DNA methylation, 
histone post-translational modifications, or histone variant incorporation (Metivier et al. 2003, 2008; Hajkova et al. 2008; Suganuma and Workman 2008). Indeed, these "chromatin marks" are thought to be involved in a functional dialogue with chromatin-binding factors in which one influences the presence of the other to finely tune the activity of cis-regulatory elements in space and time. In this context, using FOXA1-dependent enhancers as a model, we sought to define the involvement of epigenetic marks in the dynamic control of enhancer activation.

\section{Results}

\section{Discrete DNA hypomethylation is linked to cell-type-specific FOXAl recruitment to chromatin}

In order to better characterize the chromatin structure associated with FOXA1 cell-type-specific recruitment to the genome, we first looked at histone $\mathrm{H} 3$ dimethylated on lysine 4 (H3K4me2) and at the histone variant H2AFZ (H2A histone family member $\mathrm{Z}$, previously called H2AZ), which have both been described as hallmarks of enhancers (Barski et al. 2007; Heintzman et al. 2007). For instance, H2AFZ may facilitate transcription factor binding to enhancers by rendering specific nucleosomes more labile (He et al. 2010). Hence, we monitored the levels of these epigenetic marks at FOXA1-binding sites unique to MCF7 breast cancer or $\mathrm{LNCaP}$ prostate cancer cells (called MCF7-specific or LNCaPspecific) or at sites bound by FOXA1 in both cell-types (called shared) (Fig. 1A), as defined in Lupien et al. (2008). We used our previously published genomic analyses of H3K4me2 distribution in these cell lines (Lupien et al. 2008; He et al. 2010) or newly obtained ChIP-chip (chromatin immunoprecipitation coupled to hybridization of the DNA onto tiling arrays) data for H2AFZ. We found that both $\mathrm{H} 3 \mathrm{~K} 4 \mathrm{me} 2$ and H2AFZ were enriched at FOXA1-binding sites and that cell-typespecific FOXA1 recruitment correlated with differential levels of these marks (Fig. 1B,C).

Interestingly, H2AFZ and H3K4me2 have been shown to exhibit a mutually exclusive distribution with DNA methylation (Okitsu and Hsieh 2007; Ooi et al. 2007; Zilberman et al. 2008; Edwards et al. 2010; Thomson et al. 2010; Zemach et al. 2010). DNA methylation consists of the presence of 5-methylcytosines within the genome and represents an epigenetic
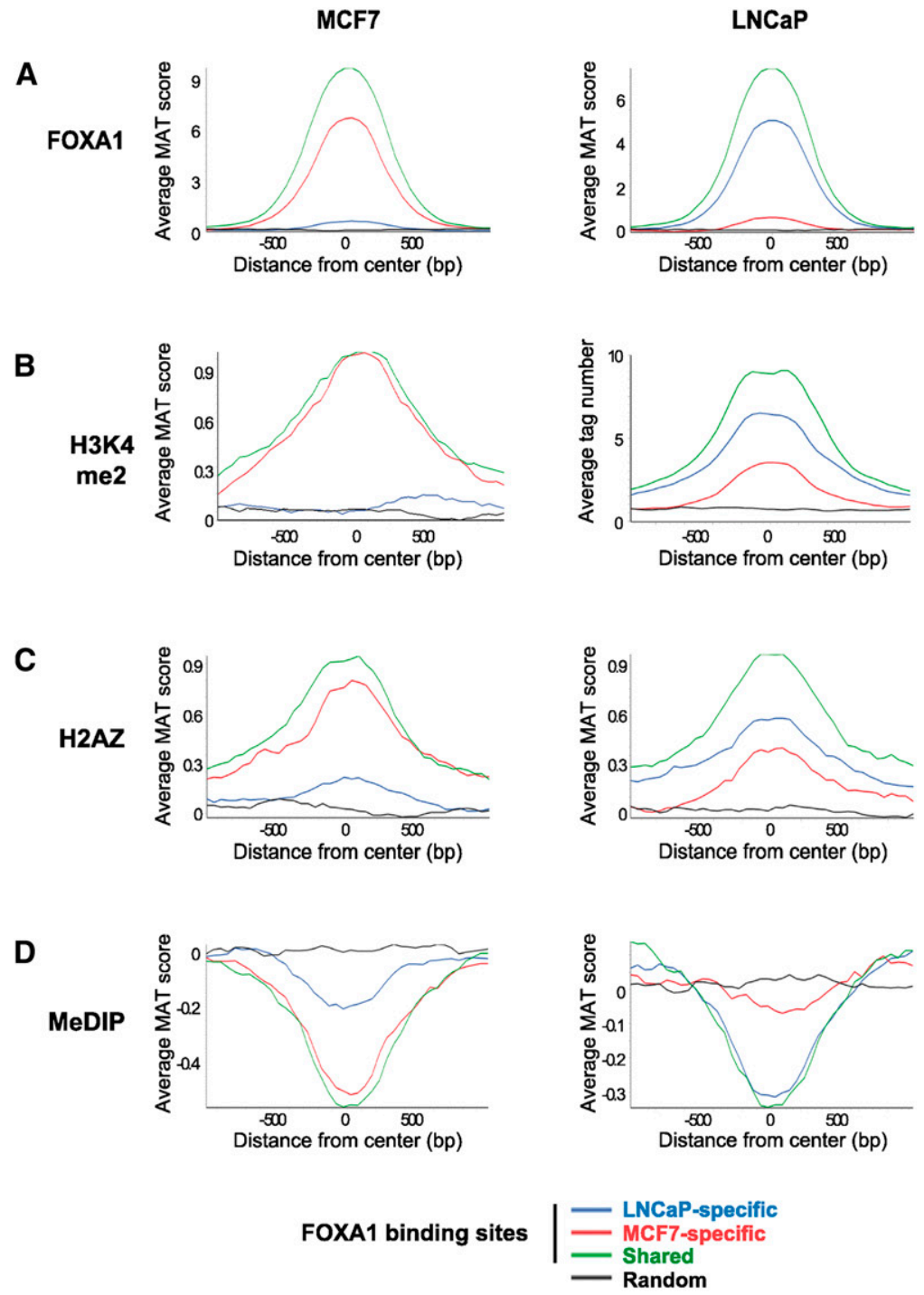

E

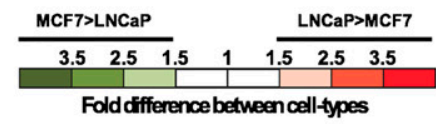

FOXA1 binding sites

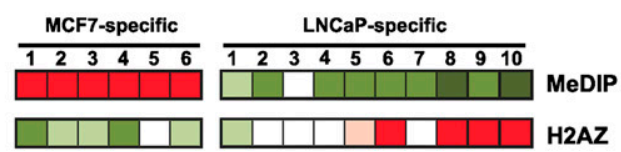

Figure 1. Differential H2AFZ and DNA methylation levels are linked to cell-type-specific FOXA1 recruitment to chromatin. Average FOXA1 $(A), \mathrm{H} 3 \mathrm{~K} 4 \mathrm{me} 2(B), \mathrm{H} 2 \mathrm{AFZ}(C)$, and DNA methylation $(D)$ enrichment levels at MCF7-specific, LNCaP-specific, or shared FOXA1-binding sites. Average signals were determined from tiling array data obtained in MCF7 and LNCaP cells as described in the Methods section except for $\mathrm{H} 3 \mathrm{~K} 4 \mathrm{me} 2$ data in LNCaP cells, which were obtained from the ChIP-seq data of He et al. (2010). A random set of regions from chromosomes 8, 11, and 12 was also analyzed. (E) MeDIPqPCR and H2AFZ ChIP-qPCR were performed in both MCF7 and LNCaP cells. For each analyzed FOXA1binding site, the strongest enrichment was divided by the one obtained in the other cell type. A color code was used to show fold differences between the two cell types for both MeDIP and H2AFZ levels. Fold differences were inferred from data obtained in three independent experiments.

\section{Genome Research} www.genome.org 
mark of central importance since it triggers the formation of inactive chromatin structures and is the only one known to be mitotically inherited (Klose and Bird 2006; Cedar and Bergman 2009; Jones and Liang 2009). Therefore, we decided to interrogate on a genome-wide scale whether DNA methylation could be involved in the control of FOXA1-dependent enhancers using MeDIP-chip (immunoprecipitation of 5-methylcytosine and hybridization of the immunoprecipitated DNA onto tiling arrays) (Weber et al. 2005, 2007). Interestingly, we found that FOXA1-bound enhancers are overall hypomethylated when compared to flanking genomic regions (Fig. 1D). This hypomethylation was not due to a marked lower CpG content at FOXA1-binding sites (Supplemental Fig. S1). Moreover, differential FOXA1 binding was linked to differential DNA methylation levels between MCF7 and LNCaP cells (Fig. 1D). Similar observations were made when analyzing genome-wide DNA methylation data from MCF7 cells generated in an independent study using MeDIP-seq (Supplemental Fig. S2; Ruike et al. 2010). Moreover, results of MeDIP-qPCR at 16 cell-type-specific FOXA1-binding sites from MCF7 or LNCaP cells were in line with the genomic-scale data (Fig. 1E). H2AFZ ChIPqPCR also confirmed its inverse relationship with DNA methylation at cell-typespecific FOXA1-binding sites (Fig. 1E).

We next sought to confirm differential DNA methylation levels at cell-typespecific FOXA1-binding sites using two additional approaches. First, we monitored the sensitivity of CpG-dinucleotide-containing CCGG sequences found within MCF7- or LNCaP-specific FOXA1-binding sites to digestion by the methylationsensitive restriction enzyme HpaII. As shown in Figure 2A, DNA prepared from MCF7 cells was significantly more digested than that prepared from LNCaP cells at MCF7-specific sites, while the opposite pattern was observed at LNCaP-specific sites. Second, we performed bisulfite pyrosequencing in order to determine the actual percentage of 5-methylcytosine at CpGs present within cell-type-specific FOXA1 recruitment regions (Fig. 2B; Supplemental Fig. S8A,B). We found that 5-methylcytosine levels were significantly lower for almost all CpGs analyzed within the cell line that recruit FOXA1 to the corresponding site (Fig. 2B).

In prostate cancer, progression from an androgen-dependent to an androgen-independent state is linked to regulation of a different transcriptional program by FOXA1 and AR (Wang et al.

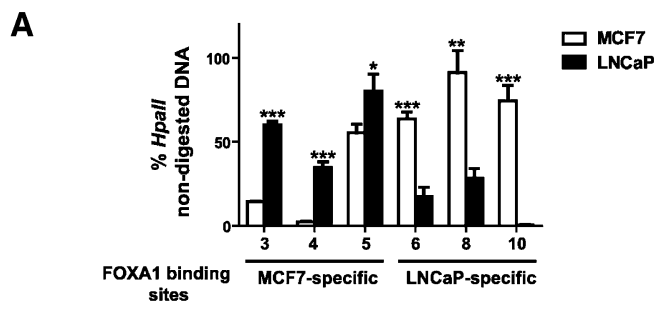

B

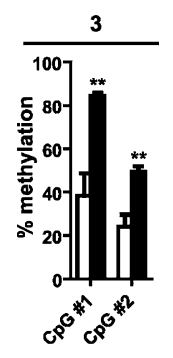

8
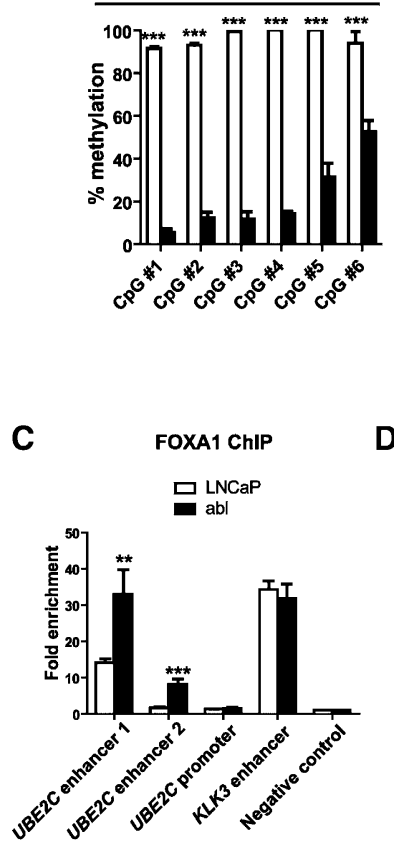

D
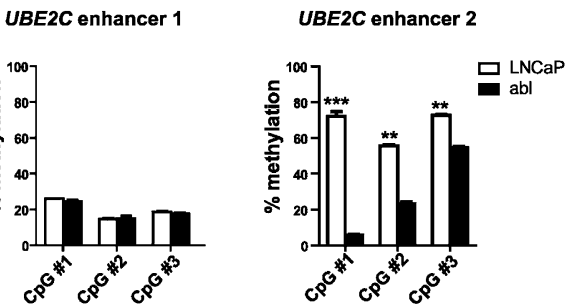

Figure 2. Differential 5-methylcytosine levels within CpGs present at cell-type-specific FOXA1-binding sites. (A) Genomic DNA from MCF7 or LNCaP cells were subjected to Hpall digestion. The percentage of non-digested DNA was determined by qPCR using primers allowing for amplification of a DNA fragment encompassing a CCGG motif localized within cell-type-specific FOXA1-binding sites. Numbering of FOXA1-binding sites is consistent with Figure 1E. Results are means and standard deviations from three independent experiments. $(B)$ The percentage of cytosine methylation for $\mathrm{CpG}$ dinucleotides found within $200 \mathrm{bp}$ of the center of cell-type-specific FOXA1-binding sites was determined using bisulfite pyrosequencing. Two MCF7- and two LNCaP-specific sites were analyzed as described in the Methods section. Numbering of FOXA1-binding sites is consistent with Figure 1E. Results are means and standard deviations from a representative experiment performed in triplicates. (C) FOXA1 ChIP-qPCR experiments were performed in LNCaP and abl cells. Fold enrichments relative to a negative control region are indicated. Results are means and standards deviations from three independent experiments. $(D)$ The percentage of cytosine methylation within $\mathrm{CpG}$ dinucleotides found near the center of UBE2C enhancers 1 and 2 was determined using bisulfite pyrosequencing in LNCaP and abl cells as indicated. Results are means and standard deviations from a representative experiment performed in triplicates. 
preferentially recruit FOXA1 and AR in the androgen-independent LNCaP-abl (abl) cells (Culig et al. 1999) compared to the maternal LNCaP androgen-dependent cells (Wang et al. 2009). For instance, FOXA1 binding to UBE2C enhancer 2 was only significantly observed in abl cells (Fig. 2C). Interestingly, using bisulfite pyrosequencing, we found that this was correlated with a dramatic decrease in CpG-enclosed 5-methylcytosine at this enhancer (Fig. 2D; Supplemental Fig. S8C). This suggests that important changes in DNA methylation in cancer may not only target promoters but also enhancers.

Hence, altogether these data indicate that cell-type-specific recruitment of FOXA1 to enhancers is associated with their discrete DNA hypomethylation. Of note, recent studies indicated that tissuespecific DNA methylation is mainly observed at intergenic regions (Lister et al. 2009; Schmidl et al. 2009). Interestingly, we also found a genome-wide correlation between cell-type-specific DNA hypomethylation and differential binding of CCCTC-binding factor (CTCF) (Supplemental Fig. S3), the key TF binding to insulators (Phillips and Corces 2009). Therefore, control of DNA methylation might be an important mechanism for establishment of cell-type-specific distal cis-regulatory elements. We had previously shown that under standard cell culture conditions, a subset of the FOXA1bound enhancers remains inactive because they could, for example, require specific stimuli (Eeckhoute et al. 2009a). Interestingly, we found that this subset of sites nevertheless showed DNA hypomethylation (Supplemental Fig. S4). This suggests that, reminiscent of FOXA1 binding (Eeckhoute et al. 2009a), DNA hypomethylation may be necessary but not sufficient for functional activities of enhancers.

Low DNA methylation levels facilitate chromatin binding of ectopically expressed FOXA1

In order to further explore the role of DNA methylation in controlling FOXA1 binding to chromatin, we stably expressed FOXA1 in MDA-MB231 cells that normally lack detectable levels of this TF (Fig. 3A; Eeckhoute et al. 2006; Badve et al. 2007; Thorat et al. 2008; Malik et al. 2010). Then, using ChIP-chip, we identified the genomic regions that were able to recruit ectopically expressed FOXA1 in this cellular background. As shown in Figure 3B, FOXA1-binding sites in MDA-MB231 only partially
B

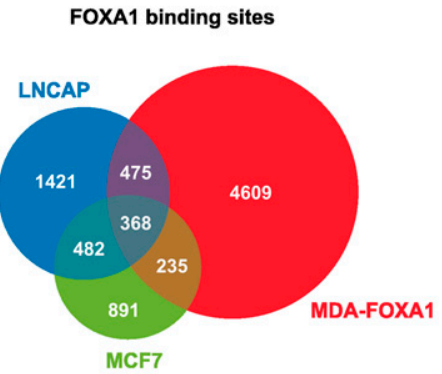

C

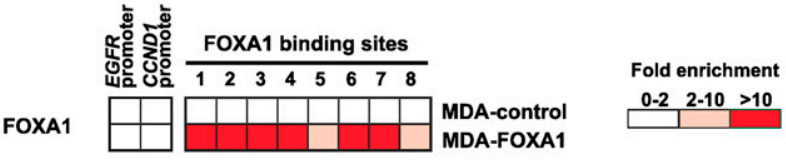

D

$\mathbf{E}$
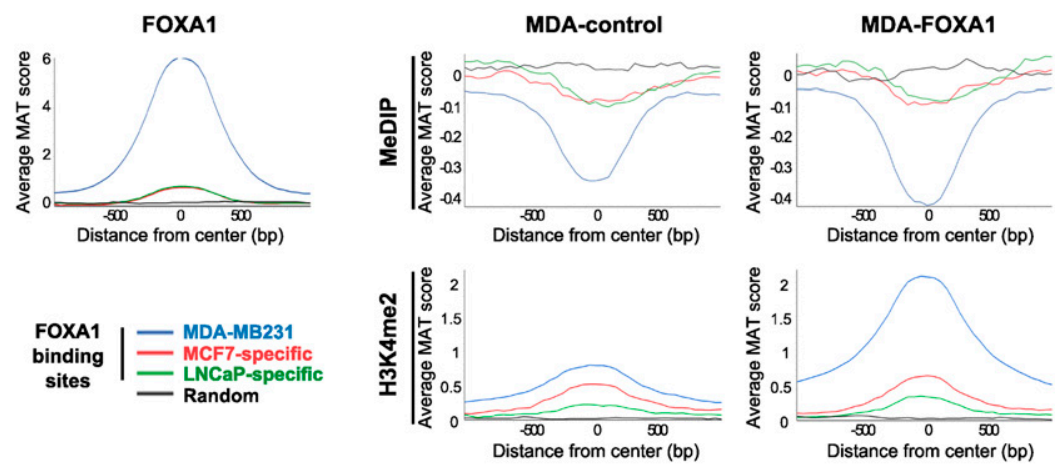

$\mathbf{F}$

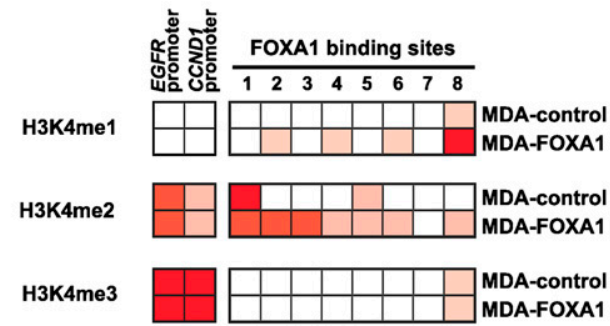

Fold enrichment

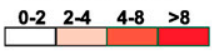

Figure 3. FOXA1 preferentially binds to DNA hypomethylated sites when ectopically expressed in MDA-MB231 cells. (A) Western blot assay showing FOXA1 expression in stably transfected MDA-MB231 cells (MDA-FOXA1). Note that only a faint non-specific band of lower molecular weight is observed in MDA-MB231 cells stably transfected with an empty vector (MDA-control) when the anti-FOXA1 antibody was used. (B) Peaks of FOXA1 enrichment were called using MAT at FDR 1\% in MDA-FOXA1 cells and compared to those previously identified in MCF7 and LNCaP cells. Numbers of overlapping and non-overlapping binding sites are indicated on the Venn diagram. (C) ChIP-qPCR validation of eight sites identified by FOXA1 ChIP-chip in MDA-FOXA1. Fold enrichments relative to negative control regions are indicated. Results are from two independent experiments. $(D)$ Average FOXA1-binding levels at MDA-MB231, MCF7-specific, or LNCaP-specific FOXA1 peaks were determined from ChIP-chip data obtained in MDA-FOXA1 cells. A random set of regions from chromosomes 8, 11, and 12 was also analyzed. ( $E$ ) Average DNA methylation and H3K4me2 levels at FOXA1-binding sites from MDA-FOXA1 cells or at sites specific to MCF7 or LNCaP cells. MeDIP-chip or H3K4me2 ChIP-chip data were obtained in MDA-control or MDA-FOXA1 cells, as indicated. A random set of regions was used as control. $(F)$ ChIP-qPCR experiments were performed in both MDA-control and MDA-FOXA1 cells to determine H3K4me1, 2, and 3 levels at FOXA1-binding sites validated in panel C. Fold enrichments relative to negative control regions are indicated. Results are from three independent experiments.

\section{Genome Research} www.genome.org 
MDA-MB231 cells using MeDIP-chip. We found that binding sites from MCF7 or LNCaP cells unable to strongly recruit FOXA1 in MDA-MB231 cells (called MCF7-specific and LNCaP-specific, respectively) showed only modest DNA hypomethylation (Fig. $3 \mathrm{D}, \mathrm{E})$. On the other hand, FOXA1 binds to chromatin regions showing low DNA methylation levels in both control and FOXA1transfected MDA-MB231 cells (Fig. 3E). In this case, this could be partly accounted for by a lower CpG density at these sites (Supplemental Fig. S1). Alternatively, we cannot rule out that DNA hypomethylation at FOXA1-binding sites may stem from the presence of FOXA2 in MDA-MB231 cells (Supplemental Fig. S5; Motallebipour et al. 2009). Nonetheless, this suggests that ectopically expressed FOXA1 binds in an opportunistic manner to chromatin regions showing intrinsic or previously acquired low DNA methylation levels. Of note, most genes found near the validated FOXA1-binding sites were not regulated in MDA-MB231 cells further, suggesting that these sites were not genuinely active cis-regulatory elements (Supplemental Fig. S6; Supplemental Table S1).

Interestingly, despite these findings, we noticed that there was a $25 \%$ further reduction in DNA methylation levels at FOXA1-binding sites in FOXA1-expressing cells compared to the control MDAMB231 cells $(p<0.001)$ (Fig. 3E). This was correlated with an overall increase in H3K4me2 levels at FOXA1-binding regions (Fig. 3E), which was validated at specific sites using ChIP-qPCR (Fig. 3F). Note that H3K4me1 was also induced at four of the eight analyzed FOXA1 recruitment sites, while H3K4me3 was only detected at one of them (Fig. 3F). This is consistent with FOXA1 binding mainly to enhancers, which are characterized by the presence of $\mathrm{H} 3 \mathrm{~K} 4 \mathrm{me} 1$ and 2 but absence or low levels of H3K4me3 (Supplemental Table S1; Heintzman et al. 2007; Lupien et al. 2008).

Hence, these data point to a potential temporally controlled establishment of the epigenetic signature characterizing FOXA1-bound chromatin regions.

\section{Dynamic establishment of the} epigenetic signature at FOXA1dependent enhancers during the course of cellular differentiation

During development, FOXA1 is expressed in committed cells to initiate chromatin opening and enhancer competency (Zaret 1999). To determine how the control of DNA and H3K4 methylation relates to the activation of FOXA1-dependent enhancers during cellular differentiation, we made use of mouse pluripotent P19 cells. P19 cells are equivalent to primitive ectoderm cells in their undifferentiated

C

D (ND) Not detectable. state and give rise to neural cells when challenged with retinoic acid (RA) (Jones-Villeneuve et al. 1983; Aiba et al. 2009). FOXA1 expression is induced after stimulation of P19 cells with RA and is required for neural differentiation (Fig. 4A; Supplemental Fig. S7; Jacob et al. 1997; Tan et al. 2010). Using ChIP-chip, we identified 11 high-confidence FOXA1-binding sites in P19 cells challenged with RA for $48 \mathrm{~h}$. This limited number of identified recruitment sites when compared to our data in human cancer cells could be in part explained by significantly lower FOXA1 expression levels in P19 cells (Fig. 4A). Moreover, since neural differentiation of P19 cells requires up to 5-7 d to complete, we cannot exclude that additional sites could recruit FOXA1 at different times during this process (Steger et al. 2010; Tan et al. 2010). Nonetheless, these

A
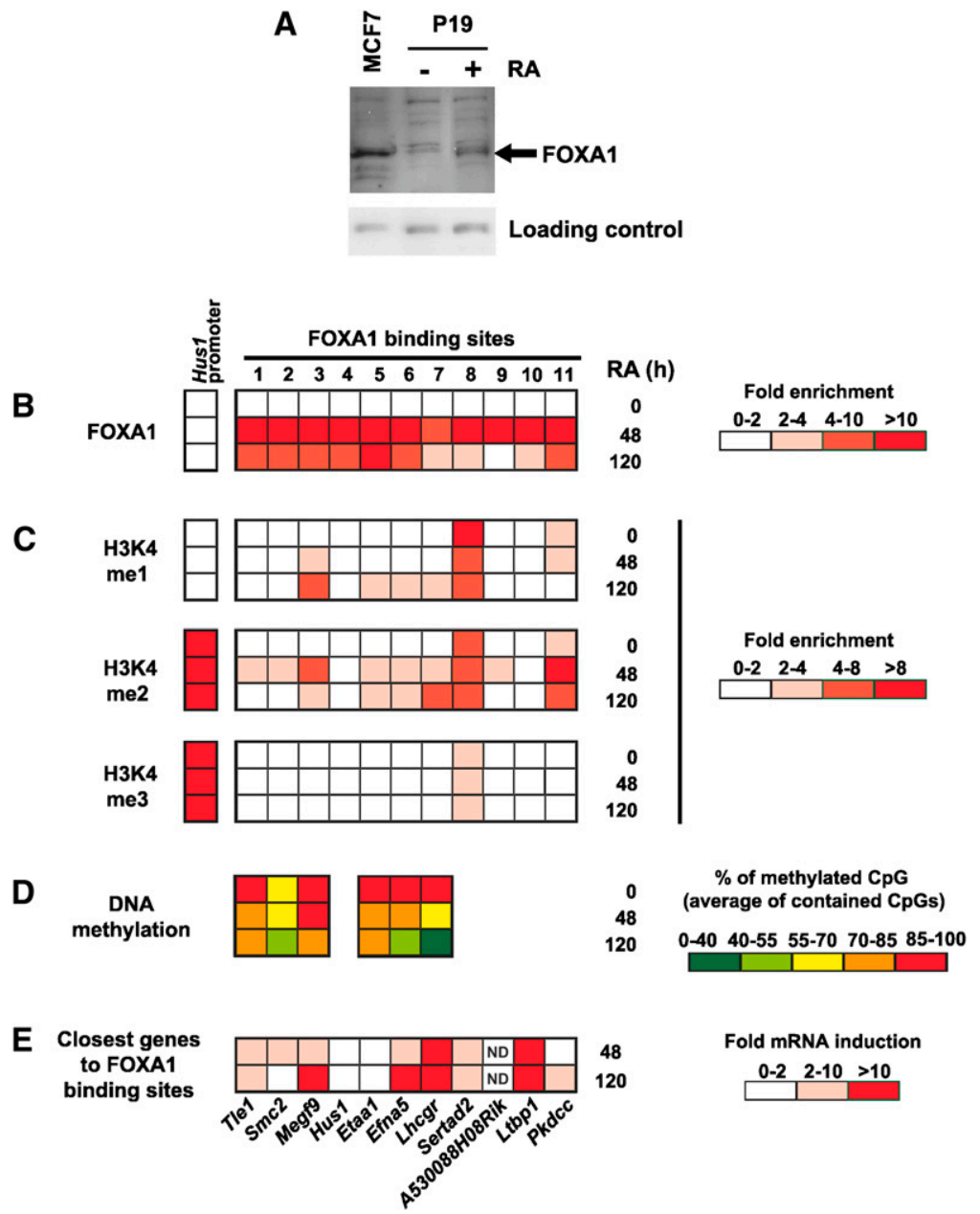

Fold mRNA induction

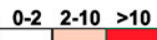

Figure 4. Epigenetic program involved in the establishment of FOXA1-dependent enhancers during cellular differentiation. $(A)$ Western blot assay showing induction of FOXA1 expression after stimulation of P19 cells with retinoic acid (RA) for $48 \mathrm{~h}$. (B) FOXA1 ChIP-qPCR experiments were performed in P19 cells stimulated (+) or not (-) with RA for $48 \mathrm{~h}$ or $120 \mathrm{~h}$. Fold enrichments relative to a negative control region are indicated. Results are from three independent experiments. (C) H3K4me1, 2, and 3 ChIPqPCR experiments performed and analyzed as in $B .(D)$ The percentage of cytosine methylation for CpC dinucleotides found within $200 \mathrm{bp}$ of the center of FOXA1-binding sites was determined using bisulfite pyrosequencing. Shown is the average methylation levels of all $\mathrm{CpG}$ s analyzed for a given binding site. (E) RT-qPCR experiments performed in P19 cells stimulated (+) or not (-) with RA for $48 \mathrm{~h}$ or $120 \mathrm{~h}$. Expression of analyzed genes was normalized using RplpO and is shown as fold induction relative to expression in undifferentiated P19 cells, which was set to 1. Results are from two independent experiments performed in duplicates. Note that, as expected, expression of the pluripotency transcription factor Nanog was strongly reduced upon induction of P19 cell differentiation with RA (data not shown). 
FOXA1 recruitment regions were validated in P19 cells using ChIPqPCR (Fig. 4B). Interestingly, we found an increase in H3K4me1 and/or 2 levels at FOXA1-binding sites in differentiating P19 cells (Fig. $4 \mathrm{C}$ ). Indeed, $\sim 60 \%$ of tested sites showed significant enrichments for H3K4me1 and/or 2 only after RA stimulation (Fig. 4C). On the other hand, only one site showed slight enrichment for H3K4me3 (Fig. 4C). Again, this is consistent with these sites being distal cis-regulatory elements (Supplemental Table S2). Interestingly, expression of the closest gene from these different FOXA1-binding sites was often (eight out of 11 genes) induced upon differentiation of P19 cells (Fig. 4E). For instance, FOXA1binding sites \#1 and 3 lie $\sim 25-30 \mathrm{~kb}$ away from the transcriptional start sites of Tle1 and Megf 9 , two genes induced in RA-treated P19 cells and previously suspected to have a role in neural differentiation (Fig. 4E; Yao et al. 1998; Brandt-Bohne et al. 2007).

The DNA methylation levels of six FOXA1-binding sites were subsequently analyzed by bisulfite pyrosequencing in both untreated and RA-stimulated P19 cells. Strikingly, we observed that these sites were highly DNA methylated in undifferentiated cells (with the exception of site 2) and were subjected to demethylation upon cellular differentiation (Fig. 4D; Supplemental Fig. S8D). Note that only a fraction of RA-treated P19 cells engage in neural differentiation, which may explain why cytosine demethylation does not necessarily reach levels observed at FOXA1-binding sites in MCF7 or LNCaP cells (Tan et al. 2010). However, this demethylation was statistically significant for most analyzed cytosines $(p<0.05)$ and was not observed at control CpGs from the Vtn promoter (Fig. 5A).

In order to better define the kinetics of events taking place during enhancer activation in differentiating P19 cells, FOXA1 recruitment as well as $\mathrm{H} 3 \mathrm{~K} 4 \mathrm{me} 2$ and DNA methylation levels were monitored in greater detail at these six FOXA1-binding sites. Hence, we performed time-course ChIP-qPCR and bisulfite-pyrosequencing experiments in which P19 cells were stimulated with RA for $6,12,18,24,48$, or $120 \mathrm{~h}$. Except for site 7, our results clearly show that FOXA1 binding to chromatin could be detected before induction of H3K4me2 and before significant DNA demethylation occurs (Fig. 5A). Delayed DNA demethylation at sites 1 and 6 was further validated using digestion of genomic DNA by the methylation-sensitive restriction enzyme HpyCH4IV (Supplemental Fig. S9). Hence, these data suggest that DNA hypomethylation may not be required for initial FOXA1 binding to enhancers but is rather established during cellular differentiation. To strengthen this conclusion, we analyzed the DNA methylation status of site 1 using DNA issued from FOXA1 ChIP performed at different times after P19 cell stimulation with RA. As shown in Figure 5B, reminiscent of input DNA, FOXA1-bound chromatin exhibited high methylation levels at the two CpGs of site 1 at early time points after RA stimulation. These data exclude the possibility that FOXA1 binding was restricted to the subset of hypomethylated sites 1 and together with Figure 5A show that FOXA1 can be initially recruited to chromatin sites comprising highly methylated CpGs.

Altogether, these data reveal a temporally controlled usage of epigenetic marks for establishment of FOXA1-dependent enhancers during cellular differentiation.

FOXAl-binding sites are intrinsic cell-type-specific enhancers whose activity is inhibited by DNA methylation

Our data suggest that DNA hypomethylation is linked to activation of FOXA1-dependent enhancers. Hence, to show that DNA methylation had a functional impact on FOXA1-dependent en-
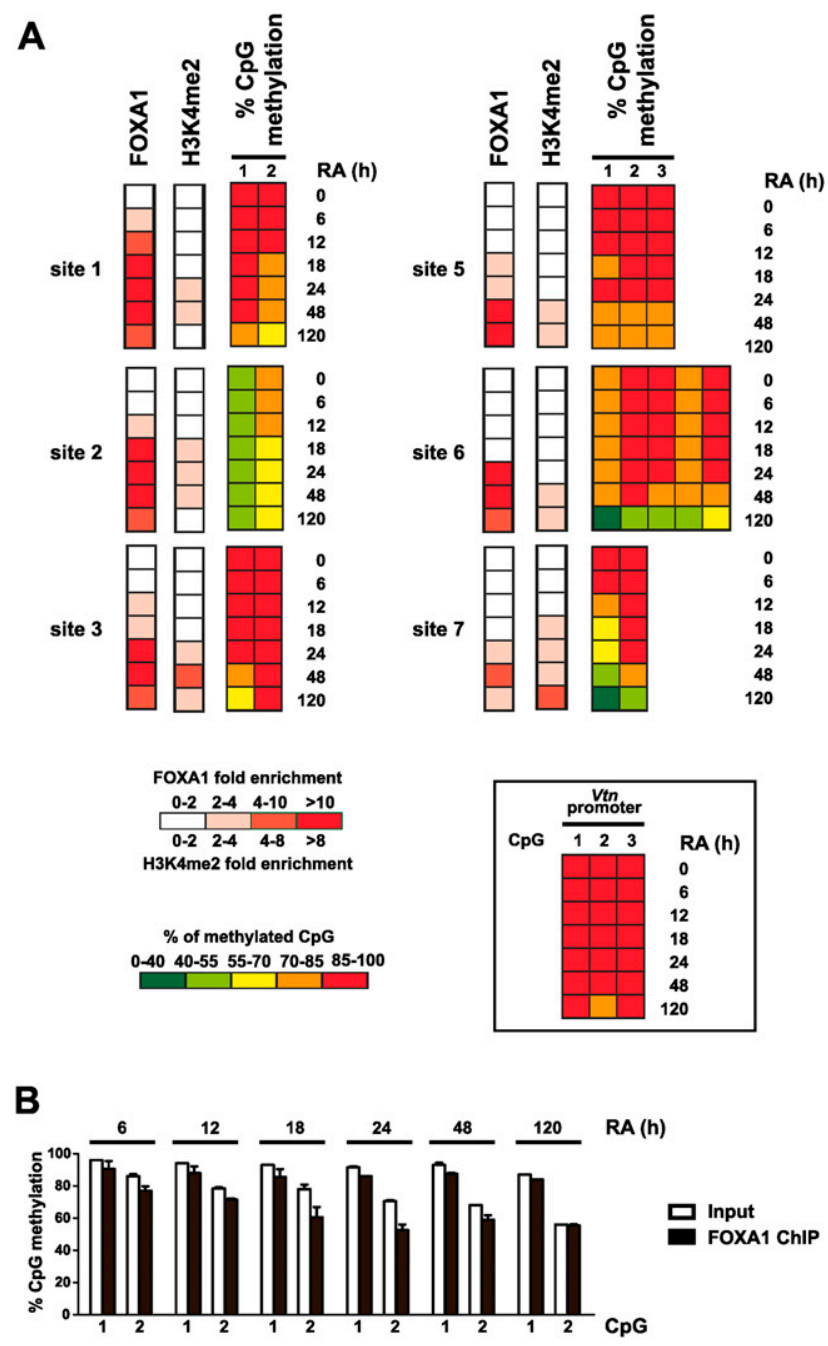

Figure 5. Kinetics of FOXA1 recruitment and epigenetic switch at enhancers during the course of P19 cell neural differentiation. $(A)$ FOXA1 and H3K4me2 ChIP-qPCR as well as bisulfite-pyrosequencing experiments were performed in unstimulated or RA-treated P19 cells and analyzed as in Figure 4. For DNA methylation data, the percentage of cytosine methylation for $\mathrm{CpG}$ dinucleotides found within $200 \mathrm{bp}$ of the center of FOXA1binding sites is indicated. Note that significant DNA demethylation ( $p<$ 0.05) was observed for all analyzed CpGs except CpG 2 of site 3. On the other hand, no significant decreases in cytosine methylation levels were obtained at control CpGs localized within the Vtn promoter (inset). These $\mathrm{CpGs}$ had been previously identified as methylated in both undifferentiated and RA-stimulated P19 cells (A Sérandour and G Salbert, unpubl.). (B) Bisulfite-pyrosequencing was used to monitor the methylation status of $C p G$ s found in site 1 within DNA issued from FOXA1 ChIP. Input DNA was used as a reference in these experiments. P19 cells were harvested and processed for ChIP assays after $6,12,18,24,48$, or $120 \mathrm{~h}$ of RA treatment, as indicated. Results are means and standard deviations from two independent experiments performed in duplicates.

hancer activities, we cloned eight FOXA1-binding sites into a CpGfree luciferase reporter plasmid in front of a minimal promoter (Supplemental Fig. S10). These constructs were then subjected to in vitro methylation by SssI and transfected into cells. We used four MCF7-specific and four LNCaP-specific FOXA1-binding sites that were transfected in the breast or the prostate cancer cell line, respectively. As shown in Figure 6A, out of six functional enhancers, five had their activities significantly blunted or abolished by DNA 
A

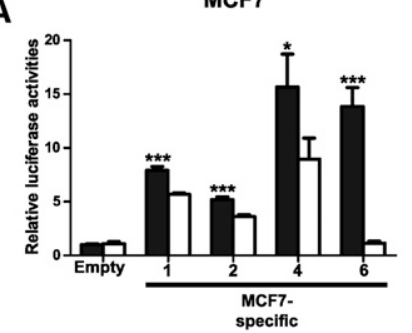

B

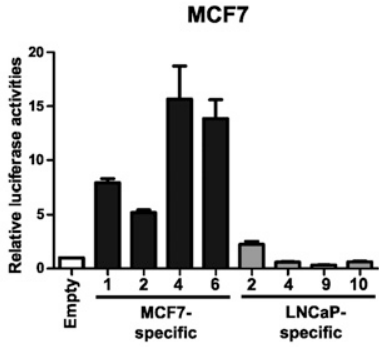

C

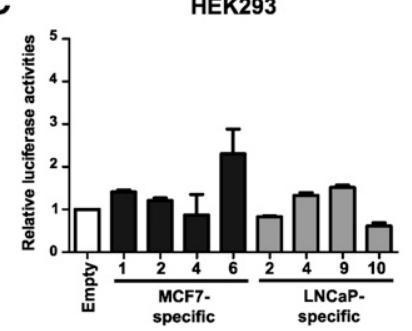

LNCaP
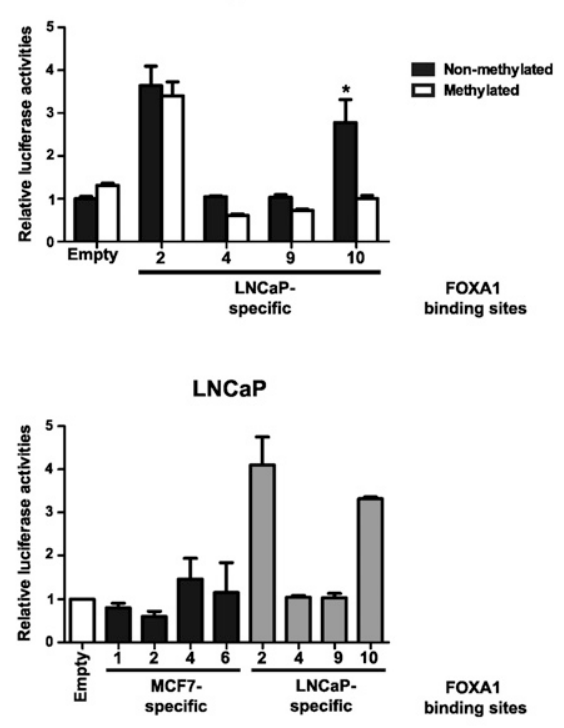

D

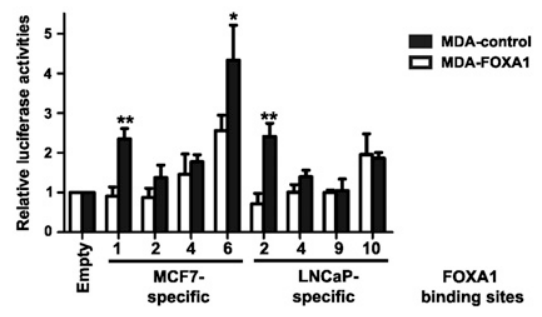

Figure 6. FOXA1-binding sites are DNA methylation- and cell-context-sensitive enhancers. $(A)$ Reporter assays were performed using in vitro methylated or unmethylated enhancers cloned within a CpG-free luciferase reporter vector and transfected in MCF7 or LNCaP cells. "Empty" refers to the control reporter construct lacking an enhancer. Numbering of FOXA1-binding sites is consistent with Figure $1 \mathrm{E}$. Results are means and standard deviations from a representative experiment performed in triplicates. (B) Reporter assays were performed using unmethylated reporter constructs that were transfected in MCF7 or LNCaP cells. Results are means and standard deviations from a representative experiment performed in triplicates. (C) Reporter assays were performed using unmethylated reporter constructs that were transfected in HEK293 cells. Results are means and standard deviations from a representative experiment performed in triplicates. $(D)$ Reporter assays were performed using unmethylated reporter constructs that were transfected in MDA-control or MDA-FOXA1 cells, as indicated. The day before transfection, $2.5 \mu \mathrm{g} / \mathrm{mL}$ tetracycline was added to the cells. Results are means and standard deviations from a representative experiment performed in triplicates. For all experiments, luciferase activities are expressed relative to that obtained for the control reporter plasmid lacking an enhancer, which was set to 1 .

methylation, validating its important regulatory function. Note that two LNCaP-specific sites did not show significant enhancer activities, which is in line with our previous study showing that, at least under standard cell culture conditions, some FOXA1-bound enhancers remain inactive (Eeckhoute et al. 2009a).

We subsequently made use of the non-methylated constructs to test whether lack of DNA methylation would allow enhancers to be active irrespective of the cell type. However, we found that the non-methylated enhancers recapitulated their cell-type-specific activities observed within the chromatin context. Indeed, MCF7specific or LNCaP-specific FOXA1-binding sites had minimal activities when transfected into the LNCaP or MCF7 cells, respectively (Fig. 6B). Moreover, these enhancers were also inactive in the HEK293 embryonic kidney and MDA-control breast cancer cells (except for some low activities of MCF7-specific binding site \#6) (Fig. 6C,D). Moreover, FOXA1 overexpression in MDA-FOXA1

cells could only partially rescue the activity of a subset of these enhancers (Fig. 6D). Hence, DNA demethylation of FOXA1-binding sites is a prerequisite to their activities, which also require specific cellular backgrounds, which most probably provide the appropriate sets of collaborating transcriptional regulatory factors. In line with this conclusion, treatment of P19 cells with the DNA demethylating drug 5-aza-2'-deoxycytidine was not sufficient to recapitulate the pattern of gene induction observed in differentiating P19 cells stimulated with RA (Supplemental Fig. S11).

\section{Discussion}

FOXA1 is believed to scan chromatin and to be able to bind to its recognition motif in condensed structures (Cirillo et al. 2002; Sekiya et al. 2009). FOXA1 subsequently triggers enhancer competency through cooperation with additional pioneer factors including GATA family members (Zaret 1999; Cirillo et al. 2002). In ESR1-positive breast cancer cells, for example, GATA3 is highly expressed and is co-recruited with FOXA1 to cell-typespecific enhancers (Lacroix and Leclercq 2004; Eeckhoute et al. 2007; Hua et al. 2009). This is in line with establishment of active enhancers by SPI1 (also called PU.1) in macrophages and B-cells (Heinz et al. 2010). Indeed, SPI1 collaborates with a small set of cell-type-specific TFs to trigger functional competency of different enhancers in these two distinct cellular lineages (Heinz et al. 2010). Therefore, a requirement for multiple cooperating pioneer factors most probably underlies their cell-type-specific activities. We propose that once bound, these collaborating pioneer factors trigger enhancer transcriptional competency through induction of an epigenetic switch (Fig. 7).

In a recent study, Edwards et al. (2010) did not find DNA hypomethylation at enhancers and argued that DNA methylation was unlikely to have a role in control of their activities during development. However, these investigators used enhancers previously mapped in cell lines of different origins from the tissues that served to generate the DNA methylation data (Heintzman et al. 2009). Since enhancers are highly cell type specific, this might explain why these regions did not show DNA hypomethylation in this study (Heintzman et al. 2009). In contrast, our data indicating that FOXA1-bound enhancers consist of locally DNA hypomethylated regions are in line with Lister et al. (2009). Strikingly, we further show that, on a genomic scale, differential DNA hypomethylation defines cell-type-specific FOXA1-binding sites. Importantly, we present evidence that, during cellular differentiation, activation of FOXA1-dependent enhancers is accompanied by a decrease in DNA methylation. Several observations point 


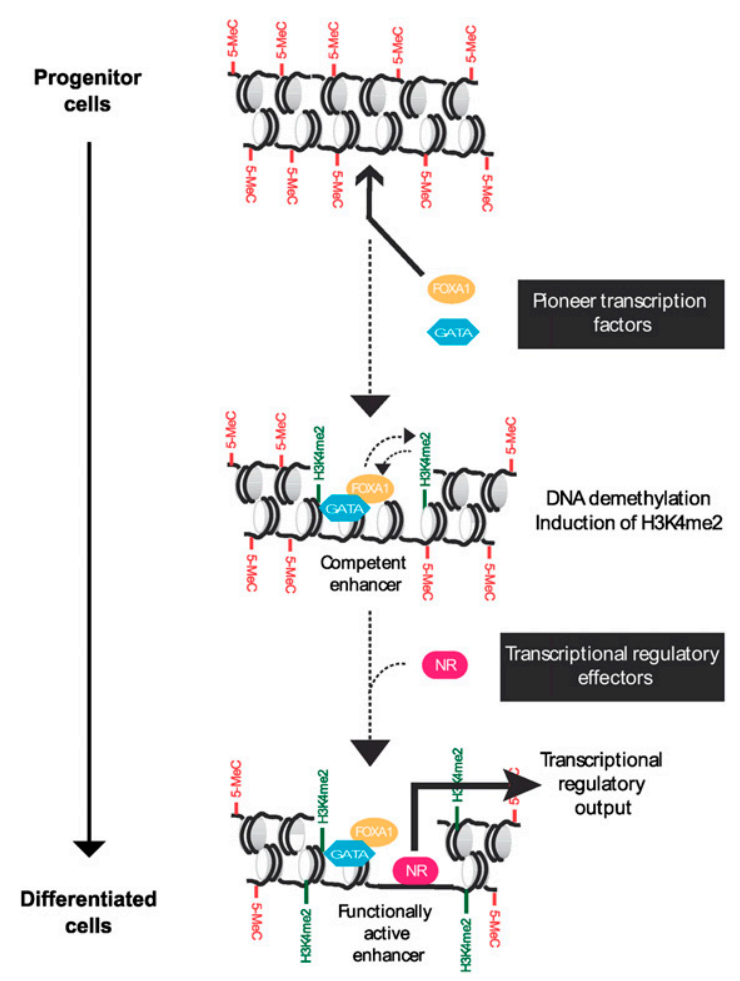

Figure 7. Model depicting the proposed dynamic TF binding and epigenetic hierarchy that governs establishment of FOXA1-dependent enhancers. FOXA1 collaborates with additional pioneer factors (e.g., GATA family factors) to trigger transcriptional competency of specific enhancers. We propose that this involves the initiation of an epigenetic switch consisting of DNA demethylation and induction of H3K4 methylation. These epigenetic changes allow for subsequent recruitment of transcriptional regulatory effectors, among which are nuclear receptors (NR) that directly regulate gene expression in response to environmental cues. See the Discussion section for further details.

to a role for DNA hypomethylation in stabilization of FOXA1 binding to chromatin. For instance, when ectopically expressed in a cell type where it lacks relevant collaborating TFs and functions, FOXA1 binding to chromatin is facilitated by preexisting low DNA methylation levels. Moreover, DNA hypomethylation was found at competent but transcriptionally inactive FOXA1-bound enhancers in MCF7 cells. Concomitantly to DNA demethylation, H3K4 methylation is induced at FOXA1 recruitment sites. This is in agreement with their description as antagonistic epigenetic marks (Okitsu and Hsieh 2007; Ooi et al. 2007; Thomson et al. 2010). Of note, erasure of H3K4me2 leads to a decrease in FOXA1 binding to enhancers (Lupien et al. 2008; Wang et al. 2009). Therefore, we propose that activation of FOXA1-dependent enhancers requires an epigenetic switch that both stabilizes the pioneer factor binding and allows for subsequent recruitment of direct transcriptional regulators (Fig. 7). Indeed, ESR1 also preferentially binds to DNA hypomethylated regions of chromatin (Supplemental Fig. S12), while erasure of $\mathrm{H} 3 \mathrm{~K} 4 \mathrm{me} 2$ leads to reduction in AR recruitment to enhancers (Wang et al. 2009).

Recently, Xu et al. (2009) suggested that FOXA1 binding to the $A l b$ enhancer was dependent on hypomethylation of a single CpG that stemmed from the presence at this site of another Forkhead family member (FOXD3) in undifferentiated cells. However, in our differentiation model, we found that most CpGs located in the vicinity of the FOXA1-binding motifs were relatively highly methylated in undifferentiated cells and were subjected to demethylation upon differentiation. Moreover, although it is expressed in undifferentiated P19 cells, we were not able to detect FOXD3 recruitment to these FOXA1-binding sites (data not shown). The hypomethylated CpG in the Alb enhancer is localized right next to the Forkhead recognition motif (cgTGTTTGC) (Xu et al. 2009), which might explain why, in this particular situation, it has to be maintained hypomethylated to allow initial FOXA1 recruitment.

Interestingly, we have shown that FOXA1-dependent enhancers are intrinsically cell type specific. Indeed, when cloned into a reporter construct, they were able to recapitulate the tissuespecific activities they normally show in the chromatin context. However, these enhancers were functionally inhibited by DNA methylation. This indicates that the complexity of TF recognition motifs at enhancers serves two distinct purposes. First, enhancers possess a specific combination of motifs required to recruit effector TFs that directly execute transcriptional regulatory activities. These combined motifs bear the cell-type-specific functions of enhancers and often allow for recruitment of TFs that respond to external stimuli such as nuclear receptors (Lupien et al. 2008; Heinz et al. 2010; Hoffman et al. 2010; Lefterova et al. 2010). Second, since DNA compaction into chromatin impedes binding of most effector TFs, enhancers also comprise recognition sites for pioneer factors whose role is to lift this inhibition and allow for execution of the regulatory function encoded into the enhancer sequence (Fig. 7).

In conclusion, we have uncovered dynamic epigenetic modifications of chromatin that occur during activation of FOXA1dependent enhancers. In particular, we have shown that DNA demethylation and induction of H3K4 methylation upon pioneer factor binding potentiate the intrinsic cell-type-specific activities of enhancers.

\section{Methods}

\section{Cell treatments and establishment of stable clones}

Differentiation of embryonal carcinoma P19 cells was induced using treatment with $1 \mu \mathrm{M}$ of all-trans retinoic acid (Sigma) (Tan et al. 2010). Exposure of P19 cells to $2.5 \mu \mathrm{M}$ 5-aza-2'-deoxycytidine (Sigma) was carried out during $48 \mathrm{~h}$. The media was changed and a new drug was added after $24 \mathrm{~h}$.

To generate FOXA1-expressing MDA-MB231 cells, MDAMB231 cells were first stably transfected with the pcDNA6/TR vector (Invitrogen). Clones were selected using $5 \mu \mathrm{g} / \mathrm{mL}$ blasticidin (Invitrogen) and screened for tetracycline inducibility using transient transfection of pcDNA4/TO/Luc (Invitrogen) and monitoring of luciferase activities. Next, one positive clone was subsequently transfected with pcDNA4/TO/FOXA1 (pcDNA4/TO from Invitrogen containing the human FOXA1 cDNA) or the empty control plasmid. Selection of stably transfected cells was performed using a combination of $5 \mu \mathrm{g} / \mathrm{mL}$ blasticidin and $75 \mu \mathrm{g} / \mathrm{mL}$ zeocin (Invitrogen). Clones were screened for FOXA1 expression using Western blotting of cellular extracts prepared from cells grown for $2 \mathrm{~d}$ in the presence of $2.5 \mu \mathrm{g} / \mathrm{mL}$ tetracycline (Sigma).

\section{Chromatin immunoprecipitation (ChIP)}

MCF7, P19, LNCaP, or abl cells were cross-linked with 1\% formaldehyde for $10 \mathrm{~min}$ at room temperature. The cells were rinsed with cold PBS, harvested and lyzed with 1\% SDS, 10 mM EDTA, and $50 \mathrm{mM}$ Tris- $\mathrm{HCl}(\mathrm{pH} 8.1)$ containing a protease inhibitor cocktail (Roche). Chromatin fragmentation was subsequently obtained by sonicating samples for $14 \mathrm{~min}$ (30 sec on/off cycles)

\section{Genome Research} www.genome.org 
using a Bioruptor (Diagenode) set up at the highest intensity. The soluble chromatin was diluted 10 times in a buffer containing 1\% Triton, $2 \mathrm{mM}$ EDTA, $150 \mathrm{mM} \mathrm{NaCl}$, and $20 \mathrm{mM}$ Tris- $\mathrm{HCl}(\mathrm{pH}$ 8.1) and incubated overnight with antibodies. Sepharose beads (Amersham Pharmacia Biosciences) were then added to the samples together with sheared salmon sperm DNA or yeast tRNA as nonspecific competitors. After $4 \mathrm{~h}$, beads were washed as described in Carroll et al. (2005), and immune complexes were eluted using 100 $\mu \mathrm{L}$ of $1 \% \mathrm{SDS}$ and $0.1 \mathrm{M} \mathrm{NaHCO}_{3}$. Samples were incubated overnight at $65^{\circ} \mathrm{C}$ to reverse cross-linking. DNA was finally purified using the NucleoSpin Extract II kit (Macherey-Nagel). Fold enrichments were determined using qPCR and internal negative controls.

Antibodies used in ChIP assays were directed against CTCF (07-729 from Millipore), H2AFZ (Ab4174 and Ab18262 from Abcam), FOXA1 (Ab5089 from Abcam), and H3K4me1, 2, or 3 (07-436, 07-030, and 04-745 from Millipore, respectively).

\section{Methylated DNA immunoprecipitation (MeDIP)}

Genomic DNA was prepared from cultured cells using a DNA extraction kit (DNeasy Blood and Tissue kit; QIAGEN) with a supplementary step of RNase digestion. Genomic DNA was then sonicated to produce fragments ranging in size from 200 to $500 \mathrm{bp}$. Four micrograms of fragmented DNA was denatured by incubation for $10 \mathrm{~min}$ at $95^{\circ} \mathrm{C}$ and immunoprecipitated overnight at $4^{\circ} \mathrm{C}$ with $2 \mu \mathrm{g}$ of monoclonal antibody against 5-methylcytidine (MAb$5 \mathrm{MECYT}$ from Diagenode) in a final volume of $500 \mu \mathrm{L}$ of IP buffer (10 mM sodium phosphate at $\mathrm{pH} 7.0,140 \mathrm{mM} \mathrm{NaCl}, 0.05 \%$ Triton $\mathrm{X}-100)$. Immunocomplexes were captured by incubation with 40 $\mu \mathrm{L}$ of BSA-coated Protein A Sepharose beads (50\% slurry) for $2 \mathrm{~h}$ at $4^{\circ} \mathrm{C}$. Beads were subsequently washed three times with $1 \mathrm{~mL}$ of IP buffer and finally incubated with proteinase $\mathrm{K}$ overnight at $55^{\circ} \mathrm{C}$ in a buffer containing $50 \mathrm{mM}$ Tris $\mathrm{HCl}$ (pH 8.0), $10 \mathrm{mM}$ EDTA, and $0.5 \%$ SDS. Methylated DNA was recovered by phenol-chloroform extraction followed by ethanol precipitation.

\section{Analysis of immunoprecipitated DNA by hybridization on tiling arrays}

DNA was amplified using the GenomePlex Complete Whole Genome Amplification kit (WGA; Sigma) (O'Geen et al. 2006). We incorporated dUTP into the PCR mix and used the GeneChip WT Double-Stranded DNA Terminal Labeling Kit (Affymetrix) to fragment and label the DNA. DNA was then hybridized onto Affymetrix human array $\mathrm{F}$ (covering chromosomes 8,11 , and 12 ) or mouse array D (covering chromosomes 4, 11, and 17) from the GeneChip Human or Mouse Tiling 2.0R Array Set, respectively. Array hybridization and scanning were performed at the OUEST-genopole microarray core facility. Tiling array data have been submitted to the Gene Expression Omnibus (GEO) database (Series record GSE21513).

Raw tiling array data processing and peak calling were performed using the MAT software (Johnson et al. 2006). MAT also provides a normalized intensity signal level for each probe on the array (MAT score), which was used to define average intensity signals within specific enhancers. Average signals were determined by first identifying the center of the enhancers of interest and expanding the region to analyze $1 \mathrm{~kb}$ on each side. These regions were then split into 40 windows where the average MAT scores of probes were determined. As controls, randomly selected regions within the non-repetitive sequences of chromosomes covered by the DNA chips were used.

Overlap between FOXA1-binding sites identified in different cell types was determined using CEAS (Shin et al. 2009). Two binding sites were considered to overlap as long as they had one base pair in common.

\section{Hpall and HpyCH4IV digestion sensitivity analyses}

Genomic DNA was prepared using the DNeasy Blood and Tissue kit (QIAGEN). To analyze the methylation status of CCGG or ACGT sites, $400 \mathrm{ng}$ or $1 \mu \mathrm{g}$ of DNA was digested overnight at $37^{\circ} \mathrm{C}$ with 20 $\mathrm{U}$ of HpaII or $10 \mathrm{U}$ of HpyCH4IV, repectively. Control DNA did not receive the restriction enzyme. Samples were then purified using the NucleoSpin Extract II kit (Macherey-Nagel) and analyzed using real-time PCR.

\section{CpG methylation analysis by bisulfite pyrosequencing}

Genomic or immunoprecipitated DNA was modified by bisulfite using the EpiTect Bisulfite Kit (QIAGEN). Biotinylated amplicons were then produced using the high-fidelity Platinum Taq DNA polymerase (Invitrogen). Each amplicon was sequenced on Pyrosequencing PSQ 96MA (Biotage). The percentage of cytosine methylation within $\mathrm{CpG}$ dinucleotides was determined within the first $100 \mathrm{bp}$ of sequenced DNA as recommended by the manufacturer. Amplification and sequencing primers were designed with PSQ Assay Design softaware (Biotage) following the manufacturer's recommendations.

\section{Western blot assays}

Cellular lysates were prepared by incubating cells in lysis buffer (25 $\mathrm{mM}$ Tris at pH 7.5, $500 \mathrm{mM} \mathrm{NaCl}, 2 \mathrm{mM}$ EDTA, 0.5\% NP-40, and protease inhibitors) for $30 \mathrm{~min}$ at $4^{\circ} \mathrm{C}$. After sonication and centrifugation to remove insoluble debris, lysates were used for Western blot assays performed using anti-FOXA1 antibody (Ab5089 from Abcam) and anti-HSPA8 (SPA-816 from Stressgen) as a loading control.

\section{RNA preparation and reverse transcription}

RNA was prepared using TRIzol (Invitrogen) according to the manufacturer's instructions. Reverse transcription was performed using M-MLV reverse transcriptase (Invitrogen) and $\operatorname{Pd}(\mathrm{N}) 6$ random hexamers (Amersham Pharmacia Biosciences).

\section{Luciferase reporter assays}

FOXA1 recruitment sites were PCR-amplified from BACs or human genomic DNA and cloned into the CpG-free pCpGLCMV/EF1 vector by DNA ligation or by homologous recombination using the In-Fusion cloning system (Clontech) (Klug and Rehli 2006). All primer sequences used to prepare these constructs are given in Supplemental Table S2. All constructs were verified by DNA sequencing. Luciferase reporter plasmids were either mock-treated or methylated in vitro with the SssI DNA methylase for $3 \mathrm{~h}$ at $37^{\circ} \mathrm{C}$ and purified with the NucleoSpin Extract II kit (MachereyNagel). Cells were transfected in triplicates with $250 \mathrm{ng}$ of reporter plasmid and $50 \mathrm{ng}$ of Renilla control vector (pRL-Null from Promega) using JetPEI (Polyplus Transfection) in 24-well plates. After $24 \mathrm{~h}$, firefly and Renilla luciferase activities were determined using the Dual-Luciferase Reporter Assay System (Promega) on a Veritas Microplate Luminometer (Turner Biosystems). Firefly luciferase activities of individual transfections were normalized against Renilla luciferase activities.

\section{Real-time PCR (qPCR)}

Real-time PCR was performed as in Eeckhoute et al. (2006). All primer sequences are given in Supplemental Table S3. 


\section{Statistical analyses}

Statistical analyses were performed using Prism software. Statistical significance was determined using a Student's $t$-test comparison for unpaired data and was indicated as follows: $\left(^{*}\right) p<0.05 ;\left(^{(*}\right) p<0.01$; $\left.{ }^{* * *}\right) p<0.001$

\section{Acknowledgments}

We are indebted to G. Palierne and C. Brigand for technical assistance and to Dr. C. Meyer and Dr. X.S. Liu (Dana-Farber Cancer Institute, Boston, MA) for advice regarding analyses of tiling array data. We also thank Dr. Patrick Descombes (University of Geneva, Switzerland) and Dr. Catherine Chevalier (OUEST-Genopole Microarray Core Facility, Nantes, France) for their advice and help with the DNA labeling and array hybridization protocols. We acknowledge Dr. M. Klug and Dr. M. Rehli (University Hospital, Regensburg, Germany) for their generous gift of the pCpGLCMV/ EF1 vector and Dr. Z. Culig (Innsbruck Medical University, Austria) for providing us with the LNCaP-abl cells. This work was supported by funds from the Centre National de la Recherche Scientifique (CNRS), Université de Rennes 1, Région Bretagne (SAD 08HC31502), Rennes métropole (Allocation 08.503), Ligue nationale contre le cancer, and Agence Nationale de la Recherche. A.A.S. is a recipient of a fellowship from the French Ministère de l'enseignement supérieur et de la recherche.

\section{References}

Aiba K, Nedorezov T, Piao Y, Nishiyama A, Matoba R, Sharova LV, Sharov AA, Yamanaka S, Niwa H, Ko MS. 2009. Defining developmental potency and cell lineage trajectories by expression profiling of differentiating mouse embryonic stem cells. DNA Res 16: 73-80,

Badve S, Turbin D, Thorat MA, Morimiya A, Nielsen TO, Perou CM, Dunn S, Huntsman DG, Nakshatri H. 2007. FOXA1 expression in breast cancercorrelation with luminal subtype A and survival. Clin Cancer Res 13: $4415-4421$.

Barski A, Cuddapah S, Cui K, Roh TY, Schones DE, Wang Z, Wei G, Chepelev I, Zhao K. 2007. High-resolution profiling of histone methylations in the human genome. Cell 129: 823-837.

Belikov S, Astrand C, Wrange O. 2009. FoxA1 binding directs chromatin structure and the functional response of a glucocorticoid receptorregulated promoter. Mol Cell Biol 29: 5413-5425.

Brandt-Bohne U, Keene DR, White FA, Koch M. 2007. MEGF9: A novel transmembrane protein with a strong and developmentally regulated expression in the nervous system. Biochem J 401: 447-457.

Carroll JS, Liu XS, Brodsky AS, Li W, Meyer CA, Szary AJ, Eeckhoute J, Shao W, Hestermann EV, Geistlinger TR, et al. 2005. Chromosome-wide mapping of estrogen receptor binding reveals long-range regulation requiring the forkhead protein FoxA1. Cell 122: 33-43.

Cecchini KR, Raja Banerjee A, Kim TH. 2009. Towards a genome-wide reconstruction of cis-regulatory networks in the human genome. Semin Cell Dev Biol 20: 842-848.

Cedar H, Bergman Y. 2009. Linking DNA methylation and histone modification: Patterns and paradigms. Nat Rev Genet 10: 295-304.

Cheung E, Kraus WL. 2010. Genomic analyses of hormone signaling and gene regulation. Аппи Rev Physiol 72: 191-218.

Cirillo LA, Lin FR, Cuesta I, Friedman D, Jarnik M, Zaret KS. 2002. Opening of compacted chromatin by early developmental transcription factors HNF3 (FoxA) and GATA-4. Mol Cell 9: 279-289.

Crowe AJ, Sang L, Li KK, Lee KC, Spear BT, Barton MC. 1999. Hepatocyte nuclear factor 3 relieves chromatin-mediated repression of the alphafetoprotein gene. J Biol Chem 274: 25113-25120.

Culig Z, Hoffmann J, Erdel M, Eder IE, Hobisch A, Hittmair A, Bartsch G, Utermann G, Schneider MR, Parczyk K, et al. 1999. Switch from antagonist to agonist of the androgen receptor bicalutamide is associated with prostate tumour progression in a new model system. Br J Cancer 81: 242-251.

Edwards JR, O'Donnell AH, Rollins RA, Peckham HE, Lee C, Milekic MH, Chanrion B, Fu Y, Su T, Hibshoosh H, et al. 2010. Chromatin and sequence features that define the fine and gross structure of genomic methylation patterns. Genome Res 20: 972-980.

Eeckhoute J, Carroll JS, Geistlinger TR, Torres-Arzayus MI, Brown M. 2006. A cell-type-specific transcriptional network required for estrogen regulation of cyclin D1 and cell cycle progression in breast cancer. Genes Dev 20: 2513-2526.

Eeckhoute J, Keeton EK, Lupien M, Krum SA, Carroll JS, Brown M. 2007. Positive cross-regulatory loop ties GATA-3 to estrogen receptor alpha expression in breast cancer. Cancer Res 67: 6477-6483.

Eeckhoute J, Lupien M, Meyer CA, Verzi MP, Shivdasani RA, Liu XS, Brown M. 2009a. Cell-type selective chromatin remodeling defines the active subset of FOXA1-bound enhancers. Genome Res 19: 372-380.

Eeckhoute J, Metivier R, Salbert G. 2009b. Defining specificity of transcription factor regulatory activities. J Cell Sci 122: 4027-4034.

ENCODE Project Consortium, Birney E, Stamatoyannopoulos JA, Dutta A, Guigó R, Gingeras TR, Margulies EH, Weng Z, Snyder M, Dermitzakis ET, et al. 2007. Identification and analysis of functional elements in 1\% of the human genome by the ENCODE pilot project. Nature 447: 799-816.

Farnham PJ. 2009. Insights from genomic profiling of transcription factors. Nat Rev Genet 10: 605-616.

Friedman JR, Kaestner KH. 2006. The Foxa family of transcription factors in development and metabolism. Cell Mol Life Sci 63: 2317-2328.

Gao N, Zhang J, Rao MA, Case TC, Mirosevich J, Wang Y, Jin R, Gupta A, Rennie PS, Matusik RJ. 2003. The role of hepatocyte nuclear factor-3 alpha (Forkhead Box A1) and androgen receptor in transcriptional regulation of prostatic genes. Mol Endocrinol 17: 1484-1507.

Hajkova P, Ancelin K, Waldmann T, Lacoste N, Lange UC, Cesari F, Lee C, Almouzni G, Schneider R, Surani MA. 2008. Chromatin dynamics during epigenetic reprogramming in the mouse germ line. Nature 452: $877-881$.

He HH, Meyer CA, Shin H, Bailey ST, Wei G, Wang Q, Zhang Y, Xu K, Ni M, Lupien M, et al. 2010. Nucleosome dynamics define transcriptional enhancers. Nat Genet 42: 343-347.

Heintzman ND, Stuart RK, Hon G, Fu Y, Ching CW, Hawkins RD, Barrera LO, Van Calcar S, Qu C, Ching KA, et al. 2007. Distinct and predictive chromatin signatures of transcriptional promoters and enhancers in the human genome. Nat Genet 39: 311-318.

Heintzman ND, Hon GC, Hawkins RD, Kheradpour P, Stark A, Harp LF, Ye Z, Lee LK, Stuart RK, Ching CW, et al. 2009. Histone modifications at human enhancers reflect global cell-type-specific gene expression. Nature 459: 108-112.

Heinz S, Benner C, Spann N, Bertolino E, Lin YC, Laslo P, Cheng JX, Murre C, Singh H, Glass CK. 2010. Simple combinations of lineage-determining transcription factors prime cis-regulatory elements required for macrophage and B cell identities. Mol Cell 38: 576-589.

Hoffman BG, Robertson G, Zavaglia B, Beach M, Cullum R, Lee S, Soukhatcheva G, Li L, Wederell ED, Thiessen N, et al. 2010. Locus co-occupancy, nucleosome positioning, and H3K4me1 regulate the functionality of FOXA2-, HNF4A-, and PDX1-bound loci in islets and liver. Genome Res 20: 1037-1051.

Hua S, Kittler R, White KP. 2009. Genomic antagonism between retinoic acid and estrogen signaling in breast cancer. Cell 137: 1259-1271.

Jacob A, Budhiraja S, Reichel RR. 1997. Differential induction of HNF-3 transcription factors during neuronal differentiation. Exp Cell Res 234: 277-284.

Johnson WE, Li W, Meyer CA, Gottardo R, Carroll JS, Brown M, Liu XS. 2006 Model-based analysis of tiling-arrays for ChIP-chip. Proc Natl Acad Sci 103: 12457-12462.

Jones PA, Liang G. 2009. Rethinking how DNA methylation patterns are maintained. Nat Rev Genet 10: 805-811.

Jones-Villeneuve EM, Rudnicki MA, Harris JF, McBurney MW. 1983. Retinoic acid-induced neural differentiation of embryonal carcinoma cells. Mol Cell Biol 3: 2271-2279.

Klose RJ, Bird AP. 2006. Genomic DNA methylation: The mark and its mediators. Trends Biochem Sci 31: 89-97.

Klug M, Rehli M. 2006. Functional analysis of promoter CpG methylation using a CpG-free luciferase reporter vector. Epigenetics 1: 127-130.

Lacroix M, Leclercq G. 2004. About GATA3, HNF3A, and XBP1, three genes co-expressed with the oestrogen receptor-alpha gene (ESR1) in breast cancer. Mol Cell Endocrinol 219: 1-7.

Laganiere J, Deblois G, Lefebvre C, Bataille AR, Robert F, Giguere V. 2005. Location analysis of estrogen receptor alpha target promoters reveals that FOXA1 defines a domain of the estrogen response. Proc Natl Acad Sci 102: $11651-11656$.

Lefterova MI, Steger DJ, Zhuo D, Oatanani M, Mullican SE, Tuteja G, Manduchi E, Grant GR, Lazar MA. 2010. Cell-specific determinants of peroxisome proliferator-activated receptor gamma function in adipocytes and macrophages. Mol Cell Biol 30: 2078-2089.

Lister R, Pelizzola M, Dowen RH, Hawkins RD, Hon G, Tonti-Filippini J, Nery JR, Lee L, Ye Z, Ngo QM, et al. 2009. Human DNA methylomes at base resolution show widespread epigenomic differences. Nature 462: 315322.

Lupien M, Eeckhoute J, Meyer CA, Wang Q, Zhang Y, Li W, Carroll JS, Liu XS, Brown M. 2008. FoxA1 translates epigenetic signatures into enhancerdriven lineage-specific transcription. Cell 132: 958-970.

\section{Genome Research}


Malik S, Jiang S, Garee JP, Verdin E, Lee AV, O'Malley BW, Zhang M, Belaguli NS, Oesterreich S. 2010. Histone deacetylase 7 and FoxA1 in estrogenmediated repression of RPRM. Mol Cell Biol 30: 399-412.

Metivier R, Penot G, Hubner MR, Reid G, Brand H, Kos M, Gannon F. 2003. Estrogen receptor-alpha directs ordered, cyclical, and combinatorial recruitment of cofactors on a natural target promoter. Cell 115: 751-763.

Metivier R, Gallais R, Tiffoche C, Le Peron C, Jurkowska RZ, Carmouche RP, Ibberson D, Barath P, Demay F, Reid G, et al. 2008. Cyclical DNA methylation of a transcriptionally active promoter. Nature 452: 45-50.

Mirosevich J, Gao N, Gupta A, Shappell SB, Jove R, Matusik RJ. 2006. Expression and role of Foxa proteins in prostate cancer. Prostate 66: 1013-1028.

Motallebipour M, Ameur A, Reddy Bysani MS, Patra K, Wallerman O, Mangion J, Barker MA, McKernan KJ, Komorowski J, Wadelius C. 2009. Differential binding and co-binding pattern of FOXA1 and FOXA3 and their relation to H3K4me3 in HepG2 cells revealed by ChIP-seq. Genome Biol 10: R129. doi: 10.1186/gb-2009-10-11-r129.

Nakshatri H, Badve S. 2009. FOXA1 in breast cancer. Expert Rev Mol Med 11: e8. doi: 10.1017/S1462399409001008.

Nucera C, Eeckhoute J, Finn S, Carroll JS, Ligon AH, Priolo C, Fadda G, Toner M, Sheils O, Attard M, et al. 2009. FOXA1 is a potential oncogene in anaplastic thyroid carcinoma. Clin Cancer Res 15: 3680-3689.

O'Geen H, Nicolet CM, Blahnik K, Green R, Farnham PJ. 2006. Comparison of sample preparation methods for ChIP-chip assays. Biotechniques 41: 577-580.

Okitsu CY, Hsieh CL. 2007. DNA methylation dictates histone H3K4 methylation. Mol Cell Biol 27: 2746-2757.

Ooi SK, Qiu C, Bernstein E, Li K, Jia D, Yang Z, Erdjument-Bromage H, Tempst P, Lin SP, Allis CD, et al. 2007. DNMT3L connects unmethylated lysine 4 of histone H3 to de novo methylation of DNA. Nature 448: 714-717.

Phillips JE, Corces VG. 2009. CTCF: Master weaver of the genome. Cell 137: 1194-1211.

Ruike Y, Imanaka Y, Sato F, Shimizu K, Tsujimoto G. 2010. Genome-wide analysis of aberrant methylation in human breast cancer cells using methyl-DNA immunoprecipitation combined with high-throughput sequencing. BMC Genomics 11: 137. doi: 10.1186/1471-2164-11-137.

Schmidl C, Klug M, Boeld TJ, Andreesen R, Hoffmann P, Edinger M, Rehli M. 2009. Lineage-specific DNA methylation in T cells correlates with histone methylation and enhancer activity. Genome Res 19: 1165-1174.

Sekiya T, Muthurajan UM, Luger K, Tulin AV, Zaret KS. 2009. Nucleosomebinding affinity as a primary determinant of the nuclear mobility of the pioneer transcription factor FoxA. Genes Dev 23: 804-809.

Shin H, Liu T, Manrai AK, Liu XS. 2009. CEAS: cis-regulatory element annotation system. Bioinformatics 25: 2605-2606.

Steger DJ, Grant GR, Schupp M, Tomaru T, Lefterova MI, Schug J, Manduchi E, Stoeckert CJ Jr, Lazar MA. 2010. Propagation of adipogenic signals through an epigenomic transition state. Genes Dev 24: 1035-1044.

Suganuma T, Workman JL. 2008. Crosstalk among histone modifications. Cell 135: 604-607.
Tan Y, Xie Z, Ding M, Wang Z, Yu Q, Meng L, Zhu H, Huang X, Yu L, Meng X, et al. 2010. Increased levels of FoxA1 transcription factor in pluripotent P19 embryonal carcinoma cells stimulate neural differentiation. Stem Cells Dev 19: 1365-1374.

Thomson JP, Skene PJ, Selfridge J, Clouaire T, Guy J, Webb S, Kerr AR, Deaton A, Andrews R, James KD, et al. 2010. CpG islands influence chromatin structure via the $\mathrm{CpG}$-binding protein Cfp1. Nature 464: 1082-1086.

Thorat MA, Marchio C, Morimiya A, Savage K, Nakshatri H, Reis-Filho JS, Badve S. 2008. Forkhead box A1 expression in breast cancer is associated with luminal subtype and good prognosis. J Clin Pathol 61: 327-332.

Visel A, Blow MJ, Li Z, Zhang T, Akiyama JA, Holt A, Plajzer-Frick I, Shoukry M, Wright C, Chen F, et al. 2009a. ChIP-seq accurately predicts tissuespecific activity of enhancers. Nature 457: 854-858.

Visel A, Rubin EM, Pennacchio LA. 2009b. Genomic views of distant-acting enhancers. Nature 461: 199-205.

Wang Q, Li W, Zhang Y, Yuan X, Xu K, Yu J, Chen Z, Beroukhim R, Wang H, Lupien $M$, et al. 2009. Androgen receptor regulates a distinct transcription program in androgen-independent prostate cancer. Cell 138: $245-256$.

Weber M, Davies JJ, Wittig D, Oakeley EJ, Haase M, Lam WL, Schubeler D. 2005. Chromosome-wide and promoter-specific analyses identify sites of differential DNA methylation in normal and transformed human cells. Nat Genet 37: 853-862.

Weber M, Hellmann I, Stadler MB, Ramos L, Paabo S, Rebhan M, Schubeler D. 2007. Distribution, silencing potential and evolutionary impact of promoter DNA methylation in the human genome. Nat Genet 39: 457-466.

Xu J, Watts JA, Pope SD, Gadue P, Kamps M, Plath K, Zaret KS, Smale ST. 2009. Transcriptional competence and the active marking of tissuespecific enhancers by defined transcription factors in embryonic and induced pluripotent stem cells. Genes Dev 23: 2824-2838.

Yao J, Liu Y, Husain J, Lo R, Palaparti A, Henderson J, Stifani S. 1998. Combinatorial expression patterns of individual TLE proteins during cell determination and differentiation suggest non-redundant functions for mammalian homologs of Drosophila Groucho. Dev Growth Differ 40: $133-146$.

Zaret K. 1999. Developmental competence of the gut endoderm: Genetic potentiation by GATA and HNF3/fork head proteins. Dev Biol 209: 1-10.

Zemach A, McDaniel IE, Silva P, Zilberman D. 2010. Genome-wide evolutionary analysis of eukaryotic DNA methylation. Science 328: 916 919.

Zilberman D, Coleman-Derr D, Ballinger T, Henikoff S. 2008. Histone H2A.Z and DNA methylation are mutually antagonistic chromatin marks. Nature 456: 125-129.

Received July 3, 2010; accepted in revised form January 5, 2011. 


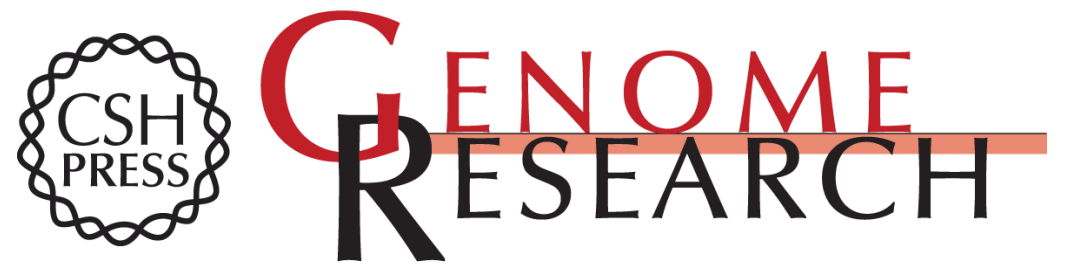

\section{Epigenetic switch involved in activation of pioneer factor FOXA1-dependent enhancers}

Aurélien A. Sérandour, Stéphane Avner, Frédéric Percevault, et al.

Genome Res. 2011 21: 555-565 originally published online January 13, 2011

Access the most recent version at doi:10.1101/gr.111534.110

Supplemental Material

References

License

Email Alerting Service
http://genome.cshlp.org/content/suppl/2011/01/13/gr.111534.110.DC1

This article cites 69 articles, 23 of which can be accessed free at: http://genome.cshlp.org/content/21/4/555.full.html\#ref-list-1

Receive free email alerts when new articles cite this article - sign up in the box at the top right corner of the article or click here.

\section{Affordable, Accurate Sequencing.}

\section{gencove}

To subscribe to Genome Research go to: https://genome.cshlp.org/subscriptions 